\title{
Genealogy as a Solution in Education
}

\section{Malcolm Noble}

Independent researcher; Shropshire, West Midlands, UK, malcolm@bookcabin.co.uk

Abstract: Genealogy contributes to learning by developing critical thinking skills. A review of three classics of genealogical literature, matched against modern tutors, confirmed that the validation and evaluation of information and the management of hypotheses have long been the core skills for family historians. A consultation with 100 genealogists revealed a preference for task orientated learning, often alone, in a self-contained environment. Reference to learning theory suggested that Genealogical Studies could be usefully offered to under achieving students in general education who respond to these conditions.

Keywords: Learning; Analysis; Investigation; Battle-Abbey-Roll; Phillimore; Tate; England

\section{Introduction}

This paper demonstrates that genealogy and the study of family history best contribute to learning not by nurturing any interest in history, culture or sociology but by developing critical thinking skills which can be transferred to other disciplines. The learning styles and environments that attract genealogists, and in which they work best, indicate where genealogy studies may be profitably offered in general education.

Genealogists quickly become adept at evaluating and processing information and are soon ready to explore further ways of interpreting what they find. The inquisitiveness, which probably enticed them to the subject in the first place, spawns a forensic approach to developing information and employing analytical techniques that would pass muster in any detective school. It need not be the role of the educationalist to mentor these attributes; I will show that they come naturally. But the educationalist should accept a role in promoting genealogy as a vehicle for the self-development of thinking skills. 
Genealogy has long been associated with learning. Sydenham Hervey spent many years transcribing documents, producing the series of the Suffolk Green Books, a forerunner of the Suffolk Records Society. From the introductions to his earliest transcripts (the Wedmore Papers), two themes emerge as the motivation for Hervey's efforts. Firstly, he saw genealogists and archivists working for the benefit of future generations, rather than their own satisfaction. And, secondly, he wanted people to somehow connect with the documents and the people that those documents refer to. ${ }^{1}$ The inter-war years saw a growth of parochial history societies in many villages and towns across England. "All over the country we find these societies some merely cover a village or group of villages, some embrace a whole county but whether large or small they all work on somewhat parallel lines. They like to get a lecturer in who can give them a talk on the history or their own village or some other local topic." 2 But there was little or no recognition of the subject in schools. The cause was subsequently picked up by the Standing Conference for Local History (1948) which argued for a higher profile for Local History in schools and colleges. W.G. Hoskins, frustrated by what he saw as restricted opportunities at Leicester (although it may seem to us that his concerns were well covered), was especially vocal in calling for greater recognition of historical solutions found through local studies. During the same period, the urgency and quality of student engagement prompted W.E. Tate to develop these subject areas. Tate was, variously, a village schoolmaster, a WEA tutor and an Oxford academic (and an 'agony aunt'); he was responsible, with only a few others, for the emergence of family and local history studies in post-war Britain. ${ }^{3}$

Examples of how genealogy can encourage further learning have usually relied on a family's connection with a recorded national event or movement, to the extent that early years students are more likely to pay attention in the schoolroom if they know that their families were affected by field enclosure, industrialisation, migration, an epidemic or a military campaign. Similarly, exploring one branch of a family tree may spark an interest in the history of a trade or a parish. I know that I would have been more interested in the school history 
of English field enclosures if I had known that the movement prompted the emigration of my family's landlord and employer casting my ancestor into nineteenth century unemployment. The genealogist's thirst for detail ignites or rekindles interests in broader history as the genealogist becomes a family historian who, in turn, becomes a local historian, probably gaining skills of palaeography and functional Latin on the way. These are indeed examples of the fruits of research leading to further learning, but this paper is not concerned with that rich and romantic vein; rather, it will demonstrate how the process of genealogical enquiry can encourage the practitioner to bring a more critical eye to their broader reading and studies.

Rather than suggesting new skills, I will acknowledge those elements of research practice that genealogists acquire with only modest experience. I will go further, arguing that genealogy offers ground for the practical development of investigative skills that can be transferred to other forum and, especially, to the sciences, including social science. I will show that as raw genealogists work to harness and exploit their curiosity, they develop skills of historical enquiry by disciplining the mind (or, at least, 'keeping it on track'), and this can be applied to broader education.

So, it is not this paper's case that genealogists should be taught new skills (indeed, I say that new skills come naturally through practice) but that they should promote genealogy as a vehicle for the promulgation of those skills.

\section{Method}

Studying the educational scope of genealogy presents an immediate problem of distinguishing between good and bad elements in genealogy. Wanting to draw on genealogical investigations which had stood the test of time, I referred to classics of genealogical literature (Burn, Phillimore, Hervey and Tate), relying on the Society of 
Genealogists' guidelines for ancestry research. The principles reflected in these works were brought together as a road map of techniques (paragraphs 9-30 follow). The relevance of these conclusions was checked against modern tutor books.

To explore and verify the context in which these working practices are played out (the working environment, research habits and aspirations), I consulted 100 genealogists. These anonymous respondents were self-selecting, and their replies were not weighted, so nothing is presented here as a rigorous survey. Rather, it is offered as evidence of a broad consultation to underpin what might otherwise have been subjective generalisations. Analysis of these responses was supported by further personal interviews. This understanding of the genealogists' skills and skill-development was considered in the context of broader learning theory.

\section{$\underline{\text { Results }}$}

\section{Validating Information}

Genealogy is an old science but, unfortunately, an old science of ill-repute, with fanciful pedigrees and poorly argued cases being presented to the public. A happy consequence of this is that modern genealogists are constantly reminded of the need to substantiate their conclusions. Several associations and societies have published checklists, designed to encourage a sound research-based approach. The Society of Genealogists (London) "has established the following principles to be essential in the conduct of acceptable genealogical research." Three of the twelve requirements refer to the strength of evidence; "the provision of clear evidence from primary sources, the use of original sources and records, and the citation and recording of sources". Another three consider the interpretation of evidence; "the logical and reasoned development of each step proved from valid evidence before further deductions are made, the investigation and analysis of all possible solutions and of contradictory evidence with each alternative hypothesis examined and tested, and the 
qualification of less certain conclusions as probable or possible so that others are not misled." The twelfth clause insists, "evidence only becomes proof through a reasoned and logical analysis and argument capable of convincing others that the conclusion is valid."

Best practice requires care not only in listing sources, but also specifying their locations and any key to their content. The measure should be facilitation of peer review. Wagner put it this way: "The statement of a family or local historian that A was the son of B may be honest and valuable - but we want to know how he knew, what was his authority. The statement of a contemporary document, on the other hand, such as a will or a record of legal proceedings, that B was A's father, is normally as good evidence as we can expect to have. For this reason, the modern critical genealogist goes out of his way to indicate the original record on which his statements rest, therein differing from those of his predecessors who quoted no authorities at all or what was neither original itself or based on what was." ${ }^{5}$

The importance of being able to trace a line of evidence was vividly shown in Phillimore's Shipway Case of 1896. Phillimore was approached by Lt. Col. Shipway and shown some Gloucestershire wills which a genealogist had uncovered as part of the evidence underpinning a pedigree of the Shipway family. It emerged that the Colonel had already paid this genealogist nearly $£_{700}$ in fees - a significant sum in Victorian England. Phillimore was familiar with Gloucestershire wills and was immediately suspicious. He embarked on his own enquiry, uncovering fabricated evidence of registers, tombstones and church memorials. It transpired that the pedigree wasn't all that was fraudulent. The genealogist Dr Herbert Davies BA MD had constructed a complete and false identity for himself - his name, history, qualifications. Phillimore reported the results of his investigation to the Probate Division. The con-man was prosecuted and was sentenced to three years penal servitude. For all his widespread contribution to genealogy, this was probably the most colourful aspect of Phillimore's career. The scandalous case brought him, for a few months, a degree of popular 
notice, if not fame, beyond the normal scope of his colleagues. But, importantly, he had established that the modern genealogist has the skill set to act as detective.

\section{Evaluating Information}

The tutor books task the entry level student with validating the earliest known generation, prompting research into the previous generation. From different decades Steele's Discovering Your Family History (1980), Hey’s Oxford Guide to Family History (1998) and Waddell's Who Do You Think You Are? (2004) were popular titles that followed the same step by step approach. A closer look at the process shows that the fledgling genealogist has adopted, probably unwittingly, the investigative cycle of Research, Analysis, Hypothesis and Proof.

Parochial records show the details of birth and baptism and, by taking the birth year of the first child, the genealogist knows when and where to look for a record of the parents' wedding. Hopefully, this will indicate the age of the parents so that the process can recommence with the new generation. Genealogists may not recognise that they have researched the initial information of the infant's birth, validating and assessing its worth, before suggesting a hypothesis about the parents' wedding which they set out to prove through further research and assessment. Research, Analysis, Hypothesis and Proof have come naturally or, at least, without pain.

In his popular handbook of the 1970s, Enjoying Archives, David Ireland ${ }^{6}$ led his readers through the different ways of classifying, storing and retrieving their family or local history data. He was presenting in popular terms the skills of identifying and managing keywords a process which had already been testing the patience of student librarians for two generations. Foskett's Subject Approach to Information set out the detailed pathways and pitfalls, largely acknowledging the work of the Cambridge Language Research Unit of that 
time. Foskett emphasised the distinction between keywords (which may appear infrequently in a document but are important for searching) and broader 'clump' words which are less effective as a search tool but nevertheless indicate the general content of a document or collection. The essence of the genealogist's work is to search and retrieve and, in best practice, share in the most accessible way and is likely to have learned to avoid the snares mentioned by Foskett with only modest experience. Quaintly, Foskett asserted that increased effort by the indexers will reduce the effort required from readers ${ }^{7}$. Subsequent decades have seen the indexers' contribution decrease as the readers gained access to increasingly sophisticated search facilities. Indeed, it is difficult to match the cynic's argument that the march of technology will make keywords redundant before we have learned how to use them properly. However, the terms of this essay draw out that, by working alone, the genealogist has acted as both the indexer and the researcher so that their management of information has been constantly field tested and their keyword skills enhanced.

When assessing the initial information, genealogists will have weighed the evidence on two criteria. Generally, they will want to assess how close their source of information was to the event and how specific the information is. The genealogist enjoys the advantage of having no 'industry standard' of evaluation. They can leave policemen to despair over the pit-falls of a shared model of evidence; family historians can worry about other matters. They may even employ different criteria for different fields of research - if they are careful to compare only like with like.

Regarding a source as 'primary' is rather like describing an antique as 'mint'. We know what we mean but, it seems, accepting a definition does not preclude us from trying to squeeze a favoured source into that definition, however uncomfortably it sits. Sydenham Hervey vividly described the problem when he prefaced his publication of Suffolk's Hearth Tax Returns for 1674. “The printer has printed from my transcript of Mr. Muskett's transcript of the original transcript of the original returns, and therefore this volume stands fifth in descent 
from the men who actually warmed themselves at these 60,000 hearths and growled at having to pay the king two shillings year by year for each of them." ${ }^{8}$ Hervey's problem is not unique. An entry in a Register of Baptisms may have been recorded immediately by the priest who performed the ceremony, or it may have been entered on the following Sunday by the Vicar from a note left by his Curate and, as early as 1862, Burn was arguing for parish registers to be original documents rather than transcriptions of the clerk's 'waste' book. ${ }^{9}$ Hervey's stepsremoved method may be one way of graduating a scale on which we may peg our source.

An assessment of the source is complimented by a measurement of how specific the information is. For example, an anonymous leaf from a family Bible fails because we cannot measure the remoteness of the source but gains ground by offering such detailed information as "Died July $22^{\text {nd }} 1892$, aged 62 years, 4 o'clock am." ${ }^{10}$ This prompts the genealogist to look for information that will strengthen the weaker information and here we need to be wary of misinterpreting corroboration. It may be that the 62 years old's death at 4 am found its way into a parish history, but unless we can show that is more than a repetition of the same story, we cannot treat it as corroboration. Two half-truths do not make one whole truth.

The classics of genealogy literature demonstrate not only that current paths of family history research have long roots but that common problems today were hardly new for the old-time scholars. I shall discuss two issues - corroboration and family tradition - because they demonstrate genealogy skills in action, yesterday and today.

\section{$\underline{\text { Some Problems of Corroboration }}$}

The Companions of the Conqueror provide the best lesson in the perils of corroboration. The original roll was prepared, following the Battle of Hastings, so that casualties and survivors could be identified, a common enough practice in warfare. That list of names was subsequently corrupted by monks and clerics susceptible to inducements. However, over the centuries, three "new" rolls found currency. 
One was compiled by John Leland, a Tudor historian and contemporary of Dugdale. Leland's work informed a contemporary Raphael Holinshed; his chronicles (published in 1577) are most popular remembered as sources for Shakespeare's history plays, although his contribution to our understanding of the English was much broader than that. The strength of Hollinshed's work was that he brought in other contributors, especially Richard Stanyhurst. A generation later, the French History Andre Du Chesne included a roll in his history. Now these three historians - Hollinshed's is considered the most useful - were working five hundred years after the event, although the names they record are sufficiently similar for us to suspect they may have used common source documents. - perhaps the Abbey Roll itself. (It was still about at the time, it seems).

Cleveland conducted a detailed analysis of the three sources for her book The Battle Abbey Roll ${ }^{11}$ and forced the conclusion that one name's appearance in the three documents is not corroboration of the knight having fought at Hastings; it is no more than evidence that his name was copied from one list to another. When historians produced a list of Companions based on more reliable evidence, they followed the approach set out above, by Hervey and called on those sources closest to the event. Believing something to be true simply because it is said repeatedly is a trap awaiting the unwary genealogist, especially if they work alone without peer review.

An internet search of genealogies produced 12 results connecting my ancestor to a particular bride. A simple check of the generation concerned with the Herald's Visitation of that same time showed that this could not have been the case. The Visitations are notorious for inaccuracy. However, when the Herald is tabulating the current generation when the facts were well known and easily sourced, we need to assess it in the same way as we treat other oral evidence.

\section{The Value of Family Tradition}


George Ewart Evans makes an especially strong case for oral history (Where Beards Wag All; The Relevance of the Oral Tradition) to the extent that a casual reader might decide never to trust a written source again. However, his terms for validating or evaluating the testimony are no different from those applied to other historical sources. How close was the informant to the reported event and was the subject was within the reporter's understanding, or are they relaying, perilously, a description or account that they do not understand? Essentially, Evans is considering the closeness of the source and the specific nature of the information, so genealogists will need no persuading to use these measures because they are the intuitive responses to the questions already on the tips of their tongues.

One unfortunate consequence of the long-lasting suspicions of genealogy is the undervaluing of information which has been proven wrong. Cleveland, for example, is ready to dismiss the truthfulness of many of the colourful stories that appear in old family histories while still considering them essential to any understanding of the family. She wrote, "I have retained the picturesque old legends that have been so long associated with them as to form part of their history. What would De Vere be without its meteor star, or De Albini without its conquered lion? I have also given all the anecdotes that I could collect, partly to relieve the inherent dullness of a mere catalogue of descents, and partly because many of them incidentally furnish vivid pictures of manners and customs long since passed away. ${ }^{12}$

Cleveland's points should not be dismissed. The history of the story is as much of the history as the story. The stories which grandma told may have been embellishments, but they said much about how the family felt about itself; we do not want to lose those "vivid pictures of manners and customs long since passed away." My own grandmother believed that her mother, who died when she was four, had been born on the wrong side of the blanket. This was untrue. Certainly, her mother had been born on the wrong side of the river and the shame of that guilty secret was shared in hushed but misunderstood terms. I have long thought that the story provides one telling picture of my grandmother's upbringing. G Ewart 
Evans, again, reports a village yarn: 'After seeing the cottage and the stable, the horseman asked, "D'you mind if I sleep with the horses?" Surely the fact that this caught the imagination of villagers and survived as a story often told, tells us more about living conditions in the parish than any proof that the conversation did or didn't take place. ${ }^{13}$

J.C. Holt devoted much of his study on Robin Hood to the development of the legend and how it reflected English society and its attitudes through the centuries; he made this more important and more interesting than the weary question of the outlaw's historical existence. We cannot divorce his summary from the value of family traditions. "A story, like an incident, can only be fully understood when set in its proper context. But, unlike an incident or set of events, a story is not fixed in time or place. It provides a continually shifting point of focus. As the circumstances which sustain it change -the audience, the means of communication, the social assumptions and conventions, the intellectual milieu - so the story itself changes" 14 There is much for the family historian to explore.

\section{Hypothesis in Genealogy}

"But I have found the pursuit of truth a path bristling with thorns, and beset with pitfalls. One of the chief difficulties to be met is the confusion caused by contradictory statements that no ingenuity can reconcile; and in too many cases conjecture alone is possible."15

Here, we see Cleveland struggling to propose a hypothesis which can be either proved or disproved. This impasse is drawn from her approach, legitimate as far as it went, of sweeping up information and seeing what she could make of it. The limitation of that approach is that, indeed, 'in too many cases conjecture alone is possible'. Genealogists have learned that a more effective method is to allow a detailed hypothesis to determine the direction of further research. In my earlier example, the birth of the eldest child directed the span of the search for the parents' wedding. 
In fact, hypotheses so readily present themselves in family history that the practitioner quickly develops a confidence in managing them. This sets the emerging genealogist apart from students in many other disciplines, where a reluctance to risk 'backing the wrong horse' can inhibit experimentation, at least in the early stages of experience. Many fledgling analysts adhere to safe hypotheses - proposals that can be easily proved but hardly take the investigation forward. The genealogist, often working alone and often over many years, has no patience with such a tender approach. Eliminating a candidate as the spouse of an ancestor seems such a step forward for the genealogist that disproving the option is accepted as good rather than disappointing news.

\section{Analysis of Interactions}

Genealogists are practised at developing facts from information (usually by drawing on documentary sources) but, too often, the world of times gone by remains a murky one, like a well vegetated fishpond where the fish are only occasionally visible from the surface. Some people may say that we will never know what goes on in the darker depths while others persevere, making the most of every sighting and gradually gaining sense of such communities. This challenges the family historian to further develop their forensic approach to research. When they stare into the murky fishpond, they need to identify links. They need information that links their ancestors to dates, places and people. They then need to prove how something at one end of the link influenced or caused something to happen at the other end; in demonstrating that interaction, they can begin to understand the world in the hidden parts of the fishpond. Now, the genealogist is working at the top end of forensic analysis and, while here may not be the place to explore the differences and values of coincidental, facilitating and causal links, family-historians-at-home every day find themselves, with no encouragement, evaluating those connections as comfortably as they manage other information. This, indeed, is the overriding strength of the discipline. 


\section{The Genealogists' Learning Environment}

Now that we understand the genealogists' skills, we can profitably consider their learning techniques. Responses from 100 family historians indicated that 91\% work alone and at home where $27 \%$ have a dedicated family history room. Only 2 respondents said that they worked mainly in a group. Only one respondent thought that genealogy's main attraction was an opportunity to meet other people. $67 \%$ had not received formal pre-school education. (During the 1950s and 1960s less than 13\% of children in England received pre-school education; ${ }^{16}$ this figure matched closely the experience of those of appropriate age in my consultation.) This suggests that the learning environment preferred by genealogists matches the self-contained, self-directed comforts in which they would have initially experimented with skills like evaluation and hypothesis. Taken together, these responses suggest what Mezirow would have called an instrumental learning style -where learners develop through experience and task orientated problem solving, without the need to negotiate space, time or a licence to speak up. ${ }^{17}$ This does not rule out the alternative, communicative learning, but shows that the skills of a genealogist can be safely developed in an instrumental atmosphere.

Following Vygotsky, who insisted that learning theory should concern itself more with "the distance between the actual development level as determined by independent problem solving and the level of potential development through problem solving under adult guidance or in collaboration with more capable peers," 18 the theorists might suggest that many genealogists are short changing themselves. I am not arguing that one learning route is better than any other. Rather, I note that the genealogist may be drawn to, and function well when, working in their own environment.

If genealogists flourish as part of a cottage industry, how do they respond to opportunities to share their product. $75 \%$ of genealogists in my consultation had shared at least part of their pedigree on line. But my consultation indicated that a generally low level of genealogists 
complied with Society of Genealogists' principles of citing primary sources when presenting their work (only $45 \%$ claimed to have quoted primary sources in more than $75 \%$ of their work). From many, including those whose responses generally reflected a studious approach to their subject, this shortcoming seemed to emerge as an almost guilty secret. Only $20 \%$ considered that the body of their work had been peer-reviewed; even within that group some allowed a low bar to define that. $40 \%$ of respondents who said their work had been peer reviewed conceded that only $50 \%$ or less of their work cited primary sources. (A repeated approach was that mere publication facilitated peer review, even where sources were not cited, and no feedback was given.) In some cases, questions about sources and peer review were seen as an unfair challenge. This resonates with Houle's work in the 1970s. "Since independent study is, by definition, a wholly self-guided way of designing and controlling an educational activity it can be examined in depth only by one who analyses his own experience or that reporting to him."19

This is probably the most criticised area of genealogy but James, Holford and Griffin offer further balance to the argument, warning of limited effectiveness when the "teacher is seeking to control the student's learning to produce the desired results. This approach produces outcomes which are conformist and to a certain extent rely on those in authority who decide what form of behaviour is correct. It may also be claimed that this approach is not very efficient in the long run because it has not encouraged learners to think for themselves but only to learn to conform to the accepted position."20

Is it fair to criticise genealogists for the little attention given to standards of practice? $54 \%$ of my consultation described family history as a hobby, while a further $23 \%$ preferred to regard it primarily as fun. Only $14 \%$ saw it primarily as an opportunity for personal development and just $8 \%$ viewed it as work. Nowhere have most family tree builders sworn to improve either genealogical practice or the reputation of genealogy - they simply want to know who their ancestors were. 


\section{$\underline{\text { Conclusions }}$}

In demonstrating that genealogy equips the practitioner with skills of validation, evaluation and hypothesis, I have purposefully drawn from examples of the classical literature of genealogy (Phillimore, Cleveland, Hervey, and Tate) showing that these are core elements in compiling the simplest of pedigrees. It is a skill set that has stood the test of time.

The "one step at a time" characteristic of pedigree building emphasises the need to move forward, in a clear direction, by proposing and proving (or disproving) a hypothesis. The study of genealogy is, therefore, a good conduit for promoting these skills. Furthermore, the cottage-industry nature of the study, often an absorbing hobby lasting many years, means that the practitioners can find themselves in an environment similar to their childhood learning experience - often, working (or playing) on their own or within a small and defined group with boundaries, with sufficient time and license to experiment with expressions of curiosity (prompting the formulation of hypotheses). We can see that the genealogy flourishes in these surroundings.

A cost of this environment is that practitioners can feel a reluctance to open their work to peer review and, even when they share their work, they often fall short in the citation of sources. For some people, a general reluctance to submit to, or enable, peer review hangs like a grey and ominous cloud over these genealogies.

The simplest explanation is that genealogists focus on building family trees rather than improving genealogical practice. Indeed, there is some impatience with standards set down by others. This reinforces the status of most genealogists as task orientated learners but, importantly, illustrates that genealogy can be an effective and comfortable medium for developing critical thinking skills, especially validation, evaluation and hypothesis, even where the student or practitioner has not signed up to any learning contract. 
So, what might have been negative responses during my consultation, draw out the essence of genealogy as a learning tool. It can flourish in comfortable surroundings, focussing on task orientated learning without the need, necessarily, for the student to negotiate permissions from other learners. And in these circumstances genealogists can find themselves working at a high level of forensic analysis.

This lends a renewed relevance to the arguments of Hoskins, Tate and others in the 1940s and 1950s, promoting family and local history studies in schools and colleges. This paper has set out good grounds for focussing on those students, often in the early teenage, who function better in task orientated learning without the need to sustain a position within the learning group. In these circumstances, at least but especially, genealogy presents a worthwhile option for developing critical thinking skills which can be carried over to other disciplines.

${ }^{1}$ Hervey, S. (1897). Wedmore Chronicle. London: Wells and Wedmore.

${ }^{2}$ Brooks, F.W. (Nov 1973). Local History 1930-1948 in Amateur Historian.

${ }^{3}$ Tate, W. E. (1967). The English Village Community and the Enclosure Movements. London: Gollancz.

${ }^{4}$ Society of Genealogists. (2017) Standards and Good Practice: Principles of Genealogical Research. https://www.sog.org.uk (Pdf accessed 10/12/2017)

${ }^{5}$ Wagner, A. (1983) English Genealogy. London: Phillimore.

${ }^{6}$ Iredale, D. (1985). Enjoying Archives: What They are, Where to Find Them, How to Use Them. London: David and Charles

Phillimore \& Co Ltd

${ }^{7}$ Foskett, (1971) (Revised) Subject Approach to Information. London: Bingley

${ }^{8}$ Hervey, S. (1905). Suffolk in 1674 being the Hearth Tax Returns. Woodbridge: Booth

${ }^{9}$ Burn, J.S. 1862 The History of Parish Registers. London: Russell Smith

${ }^{10}$ Fragment. Author's Collection

${ }^{11}$ Cleveland. (1889). The Battle Abbey Roll London: John Murray

${ }^{12}$ Cleveland. (1889). The Battle Abbey Roll London: John Murray

${ }^{13}$ Evans, G. E. (1970). When Beards Wag All the Relevance of the Oral Tradition. London: Faber

${ }^{14}$ Holt, J.C. (1984). Robin Hood London: Thames and Hudson.

${ }^{15}$ Cleveland. (1889). The Battle Abbey Roll London: . John Murray

${ }^{16}$ West, A. and Noden, P. (2016). Public funding of early years education in England: An historical perspective. (Clare Market Papers Number 21). LSE: Education Research Group Department of Social Policy. 
${ }^{17}$ Mezirow, J. Transformative Dimensions of Aduly Learning San Francisco: Jossey-Bass.

${ }^{18}$ Vygotsky, L. (1978) Mind in Society. MA: Harvard UP.

${ }^{19}$ Houle, C. (1972) The Design of Education. San Francisco: Jossey-Bass.

${ }^{20}$ James, P. Holford, J. \& Griffin C. (2003) The Theory and Practice of Learning. London:

Routledge. 